Vol. 4 (2), pp. 042-047, September, 2014

ISSN: 2276-7797; ICV: 5.98

Copyright (C2014, the copyright of this article is retained by the author(s)

DOI Link: http://doi.org/10.15580/GJMS.2014.2.062014273

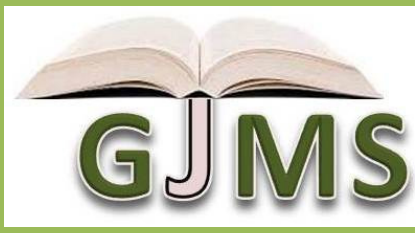

http://gjournals.org/GJMS

\title{
Neonatal Tetanus in Federal Medical Center, Ido-Ekiti, South West Nigeria in a Five Year Retrospective Study
}

\section{${ }^{* 1}$ BABATUNDE Oluwole Adeyemi, ${ }^{2}$ ADEBARA Victoria Olufunmilayo, ${ }^{3}$ ATOYEBI Oladele Ademola, ${ }^{4}$ OLUWAGBEMI Oluwagbeminiyi Abiodun}

1Department of Community Medicine, Federal Medical Center, Ido-Ekiti, Nigeria. Postal address:

P. O. Box 6170, llorin, Kwara State.

${ }^{2}$ Department of Paediatrics, Federal Medical Center, Ido-Ekiti, Nigeria.

${ }^{3}$ Department of Community Medicine, Federal Medical Center, Ido-Ekiti, Nigeria.

${ }^{4}$ Department of Family Medicine, Federal Medical Center, Ido-Ekiti, Nigeria.

Emails: 2ibuore2005@yahoo.com, 32delato_pet @yahoo.com, ${ }^{4}$ gbeminiyi1000 @yahoo.com

ARTICLE INFO

Article No.: 062014273

Type: Research

DOI: 10.15580/GJMS.2014.2.062014273

Submitted: $20 / 06 / 2014$

Accepted: 10/09/2014

Published: 20/09/2014

${ }^{*}$ Corresponding Author

BABATUNDE Oluwole Adeyemi

E-mail: wolleking@yahoo.com

Phone: +2348034314305

$+2348182874271$

Keywords:

Antenatal care, Neonate, Teenage

mothers, Tetanus
ABSTRACT

Introduction: Neonatal Tetanus, though a preventable disease through simple measures, still remains a cause of neonatal mortality in Nigeria.

Methodology: This was a review of all cases of neonatal tetanus in Federal Medical Centre, Ido- Ekiti between January 2007 and December 2012. It was performed using patients' case notes and the diagnosis of tetanus was clinical in all cases.

Results: There were six patients admitted during the five- year period. The mean age was 7.7 days. There were 5 females $(83.3 \%)$ and 1 male (16.7\%). The average number of days spent on admission in the hospital was 15.2 days with the minimum being 1 day and the maximum 33 days. The mean age at which the first spasm occurred was at 7.5 days. Only 1 $(16.7 \%)$ was delivered in a health facility, $67.7 \%$ had fomentation done on their umbilical cords, $33.3 \%$ had septic umbilical cords only $1(16.7 \%)$ was delivered in a health facility. Three of the patients were delivered in religious centres called mission homes. Five $(83.3 \%)$ of the mothers were teenagers and unmarried, $2(33.3 \%)$ had partial antenatal care, 4 $(67.7 \%)$ had no antenatal care while none of them received up to 2 doses of tetanus toxoid vaccine. The case fatality rate was $50 \%$.

Conclusion: Teenage motherhood, poor antenatal care, inadequate immunization of mothers with tetanus toxoid vaccine and poor umbilical cord care are identified as risk factors for neonatal tetanus. It should be ensured that gender equality campaigns are strengthened, traditional birth attendants trained in issues of maternal and child health, and immunization campaigns for mothers and neonates improved. 


\section{INTRODUCTION}

Neonatal Tetanus, though a preventable disease through simple measures, still remains a cause of neonatal mortality in many developing countries like Nigeria. Globally, neonatal tetanus accounts for $7 \%$ of Neonatal deaths (Oruamabo, 2007) while the incidence of the disease in Nigeria varies. In a study done in Zaria between 2005 and 2009 by Onalo et al. (2011), a prevalence of $0.7 \%$ was reported and a case fatality rate of $75.0 \%$. In another study carried out between 1998 and 2008 in Enugu, mortality from neonatal tetanus was recorded as $31.7 \%$ (Emodi et al., 2011). The identified risk factors for neonatal tetanus may be prenatal, perinatal or neonatal and include lack of appropriate antenatal care for pregnant women especially lack of vaccination with tetanus toxoid, unhygienic delivery practices, the unhygienic handling of the umbilical cord, mother's illiteracy, poor socio-economic conditions and traditional uvulectomy (Akanni et al., 2004; Dey et al., 2011).

There seems to be a variation in the way tetanus affects the sexes. Reports gathered from both hospital and community-based surveys indicate that the ratio of male to female neonatal tetanus cases worldwide usually ranges from 1:1 to $1: 3$. One possible explanation for this predominance of female over male neonates is that males may receive preferential care after birth especially in rural tropical areas (PAHO, 2005 ). Maternal age, seasonality of cases, location of the delivery and time of discharge are other factors that have been considered as having possible associations with neonatal tetanus. The probability that the mother or another person would handle the umbilical stump incorrectly is greater where the mother and the child were discharged 6 to 12 hours after delivery (PAHO, 2005).

Neonatal tetanus can be prevented by immunizing women of childbearing age with tetanus toxoid either during pregnancy or outside of pregnancy. This protects the mother and - through a transfer of tetanus antibodies to the fetus - also her baby. Immunization of pregnant women or women of childbearing age with at least two doses of tetanus toxoid is estimated to reduce mortality from neonatal tetanus by $94 \%$ (Blencowe et al., 2010). For a child to be protected throughout life, he/she should receive 3 doses of DTP in infancy, followed by a TT-containing booster at school-entry age (4-7 years), in adolescence (12-15 years), and in early adulthood (WHO, 2008).

Elimination of maternal and neonatal tetanus (MNT) is defined as a reduction of neonatal tetanus incidence to below 1 case per 1000 live births per year in every district and worldwide, all countries are committed to the elimination of MNT (WHO, 2008). In countries with effective immunization programmes and good standards of hygiene, maternal and neonatal tetanus (MNT) has been largely eliminated. The "highrisk approach" to control neonatal tetanus has been advised by the World Health Organization (2006) to be part of the neonatal tetanus elimination strategy in countries where the elimination target has not yet been reached.

In Nigeria, there is scanty information on the incidence of neonatal tetanus and not enough data to access the effectiveness of tetanus control measures. This study was carried out to study the pattern of neonatal tetanus infection in Federal Medical Centre, Ido- Ekiti to further add to available data pool.

\section{METHODOLOGY}

This review was carried out on all cases of neonatal tetanus infection in Federal Medical Centre, Ido Ekiti between January 2007 and December 2012. There were 6 patients diagnosed with neonatal tetanus out of 1130 neonates admitted into the neonatal intensive care unit during the five- year period. The review was performed using patients' case notes and the diagnosis of tetanus was clinical in all cases based on case definition criteria from previous studies (Anah et al., 2008; Roper et al., 2008). The details obtained include the age and sex of the patient, duration of admission, age of the mother, antenatal clinic attendance, records of tetanus toxoid vaccination during pregnancy, history of cord care and outcome. Ethical approval was obtained from the Ethical Committee of Federal Medical Centre, Ido Ekiti, Ekiti State and Epi Info statistical software was used to analyse the data obtained. No cross-tabulation was done because of the few number of cases of neonatal tetanus seen within this period.

\section{RESULTS}

There were 6 patients diagnosed with neonatal tetanus out of the 1130 neonates admitted during the five- year period giving a prevalence rate of $0.53 \%$. The mean age of the neonatal tetanus patients was 7.7 days with the youngest being 3 days old and the oldest 22 days. Table 1 shows the age distribution of the patients. There were $5(83.3 \%)$ females and $1(16.7 \%)$ male. The average number of days spent on admission in the hospital was 15.2 days with the minimum being 1 day and the maximum, 33 days. The mean age at which the first spasm occurred was at 7.5 days. 
Table 1: Medical History of patients

\begin{tabular}{|c|c|c|}
\hline Variable & Frequency & Percentage \\
\hline \multicolumn{3}{|l|}{ History of ANC } \\
\hline No & 4 & 66.7 \\
\hline Inadequate & 2 & 33.3 \\
\hline Yes & 0 & 0.0 \\
\hline \multicolumn{3}{|l|}{ History of TT2 } \\
\hline No & 6 & 100 \\
\hline Yes & 0 & 0.0 \\
\hline \multicolumn{3}{|l|}{ Where delivered } \\
\hline Health Centre & 1 & 16.7 \\
\hline Mission House & 3 & 50.0 \\
\hline Home & 2 & 33.3 \\
\hline \multicolumn{3}{|c|}{ Instrument for Cord Cut } \\
\hline Blade & 1 & 16.7 \\
\hline Scissors & 1 & 16.7 \\
\hline Unknown & 4 & 66.7 \\
\hline \multicolumn{3}{|c|}{ Methylated Spirit } \\
\hline Yes & 5 & 83.3 \\
\hline No & 1 & 16.7 \\
\hline \multicolumn{3}{|l|}{ Fomentation } \\
\hline Yes & 4 & 66.7 \\
\hline No & 2 & 33.3 \\
\hline \multicolumn{3}{|c|}{ Balm Application } \\
\hline Yes & 1 & 16.7 \\
\hline Missing & 5 & 83.3 \\
\hline \multicolumn{3}{|l|}{ Is cord septic? } \\
\hline Yes & 2 & 33.3 \\
\hline No & 4 & 66.7 \\
\hline \multicolumn{3}{|c|}{ Age at first symptom(NB-Not spasm) } \\
\hline 3 days & 1 & 16.7 \\
\hline 4 days & 1 & 16.7 \\
\hline 6 days & 2 & 33.3 \\
\hline 13 days & 1 & 16.7 \\
\hline 14 davs & 1 & 16.7 \\
\hline \multicolumn{3}{|l|}{ Age of Mother } \\
\hline 17 years & 1 & 16.7 \\
\hline 18 years & 2 & 33.3 \\
\hline 19 years & 2 & 33.3 \\
\hline 26 years & $\overline{1}$ & 16.7 \\
\hline \multicolumn{3}{|c|}{ Mother Marital Status } \\
\hline Single & 5 & 83.3 \\
\hline Married & 1 & 16.7 \\
\hline \multicolumn{3}{|l|}{ Outcome } \\
\hline Survived & 3 & 50.0 \\
\hline Died & 3 & 50.0 \\
\hline
\end{tabular}

While $4(67.7 \%)$ of the patients had a history of fomentation done on their umbilical cords, 2 (33.3\%) had septic umbilical cords on admission and only 1 (16.7\%) was delivered in a health facility. In table 2, three of the patients were delivered in religious centres called mission homes. Five (83.3\%) of the mothers were teenagers and unmarried, 2 (33.3\%) had partial antenatal care, $4(67.7 \%)$ had no antenatal care while none of them received up to 2 doses of tetanus toxoid vaccine. The mortality rate was $50 \%$ as 3 of the patients died while 3 survived. 
Table 2: Medical history of individual patients

\begin{tabular}{lllllllll}
\hline S/N & $\begin{array}{l}\text { Mother's } \\
\text { age (years) }\end{array}$ & Marital Status & ANC & $\mathbf{T T}_{2}$ & $\begin{array}{l}\text { Age at first } \\
\text { symptom } \\
\text { (days) }\end{array}$ & Outcome & $\begin{array}{l}\text { Age } \\
\text { presentation } \\
\text { (days) }\end{array}$ & Place of delivery \\
\hline 1 & 19 & Married & Nil & Nil & 6 & Survived & 9 & Mission \\
2 & 19 & Single & Partial & Nil & 3 & Died & 3 & Mission \\
3 & 26 & Single & Nil & Nil & 6 & Died & 7 & Health centre \\
4 & 18 & Single & Partial & 1 Shot & 4 & Died & 7 & Mission \\
5 & 18 & Single & Nil & Nil & 14 & Survived & 22 & Home \\
6 & 17 & Single & Nil & Nil & 13 & Survived & 15 & Home \\
\hline
\end{tabular}

\section{DISCUSSION}

This review showed that there were 6 patients admitted during the five- year period. The average age at presentation was 7.50 days while the average number of days spent on admission in the hospital was 15.2 days. All the patients that died in this review had the first symptom between the 3rd and 6th day of life. This is similar to what was reported by Davies-Adetugbo et al. (1998) and Oyedeji et al. (2012) who stated a significantly higher mortality in incubation period of 6 days or less. There were $5(83.3 \%)$ females and 1 $(16.7 \%)$ male. This is consistent with the female preponderance reported in previous studies and analyses of neonatal tetanus data (PAHO, 2005). This finding is also similar to that of a similar review by Peterside et al. (2012) who found that $4.7 \%$ and $95.3 \%$ of the 40 neonatal tetanus patients were males and females respectively over a period of five years in a Southern Nigerian tertiary hospital. However, other studies revealed a higher incidence among female neonates. For example, Alhaji et al. (2013) found that out of the 51 neonates seen with neonatal tetanus in a Northern Nigerian study, 30 (58.8\%) were males and 21 $(41.2 \%)$ were females. Also, Lambo et al. (2011) observed a higher incidence of neonatal tetanus in males $(74 \%)$ than in females $(25 \%)$ in rural Pakistan. The incidence of tetanus among neonates has been linked more to hygiene and cord care (Ertem et al. (2004); Asekun-Olarinmoye et al. (2003) and Ambe et al. (2009) than to gender. In developed countries with better female education, adequate vaccination coverage and neonatal care, the numbers of cases of neonatal tetanus reported were rather small when compared to developing countries. According to the CDC (2011), the United States of America reported only 1 case of neonatal tetanus between 2001 and 2008. The patient was reported to be a premature male who was delivered at home to an immigrant mother with an unknown vaccination history. The mean age at which the first spasm occurred was at 7.5 days.

In this review, $4(67.7 \%)$ of the patients had a history of fomentation done on their umbilical cords. This is an unclean method of cord care widely employed in southwestern Nigeria and which is a documented risk factor for neonatal tetanus (Oyedeji et al., 2012). Also, only $1(16.7 \%)$ was delivered in a health facility, 2 $(33.3 \%)$ at home and $3(50 \%)$ in religious houses. Many people in rural areas in Nigeria still deliver at home and with the high level of religiosity, many still turn to the religious and faith homes usually referred to as mission homes. There will be little or no medical care in the home and mission house deliveries. More needs to be done in engaging traditional birth attendants in rural communities, training them and incorporating them into all aspects of primary health care especially maternal and child health.

Five $(83.3 \%)$ of the mothers were teenagers and unmarried. This may be a pointer to the fact that teenage mothers are likely to have less family support (Cooley and Unger, 1991; Geronimus and Korenman, 1993). Antenatal care and tetanus immunization are important in neonatal tetanus elimination (Blencowe et al., 2010). Only $2(33.3 \%)$ of the mothers in this review had some level of antenatal care while $4(67.7 \%)$ had none. Also, none of them received up to 2 doses of tetanus toxoid vaccine putting their children at risk of neonatal tetanus.

The mortality rate was $50 \%$ as 3 of the patients died while 3 survived. This is similar to $56 \%, 56.2 \%$ and $57.6 \%$ mortality rates due to tetanus reported by Hassan et al. (2011), Omoigberale and Abiodun (2005) and Davies-Adetugbo et al. (1998) respectively but, slightly higher than the $43.8 \%$ and $41.8 \%$ reported by Ogunlesi et al. (2001) and Bunyamin et al. (2008) respectively.

\section{CONCLUSION}

Various factors have been associated with neonatal tetanus infection in this review and they include teenage motherhood, poor antenatal care, inadequate immunization of mothers with tetanus toxoid vaccine and poor umbilical cord care. Gender equality campaigns should be strengthened as improved care for female children may help reduce morbidity and mortality from neonatal tetanus. Engagement, training and collaboration with traditional

birth attendants on issues of maternal and child health should also be encouraged. Finally, immunization campaigns need to be strengthened for mothers and 
neonates as well to be immunized against tetanus. However, further community- based studies should be carried out to get more data and make valid assertions on the prevalence, associations and risk factors for neonatal tetanus in Nigeria.

\section{COMPETING INTERESTS}

There are no competing interests

\section{AUTHORS' CONTRIBUTIONS}

All authors participated in the conception, planning, data collection, literature review data entry and analysis and in the final write-up.

\section{REFERENCES}

Akanni NA, Nte AR, Oruamabo RS (2004). Neonatal tetanus in Nigeria: One social scourge too many! Nigerian Journal of Paediatrics. 31 (1): 1-9.

Alhaji MA, Bello MA, Elechi HA, Akuhwa RT, Bukar $\mathrm{FL}$, Ibrahim HA (2013). A review of neonatal tetanus in University of Maiduguri Teaching Hospital, North-eastern Nigeria. Niger Med J. 54(6): 398-401.

Ambe JP, Bello M, Yahya SJ, Omotara BA (2009). Umbilical cord care practices in Konduga local government area of Borno State, North-eastern Nigeria. The Internet J Trop Med. 5.

Asekun-Olarinmoye EO, Lawoyin TO, Onadeko MO (2003). Risk factors associated with neonatal tetanus in Ibadan, Nigeria - a revisit. Afr J Med Sci. 32: 275-8.

Anah MU, Etuk IS, Ikpeme OE, Ntia HU, Ineji EO, Archibong RB (2008). Post Neonatal Tetanus in Calabar, Nigeria: A 10- Year Review. Niger Med. Pract. 54: 45-47.

Blencowe H, Lawn J, Vandelaer J, Roper M, Cousens S (2010). Tetanus toxoid immunization to reduce mortality from neonatal tetanus. Int. J. Epidemiol. 39 (suppl. 1): i102i109.

Bunyamin DB, Uzun $\mathrm{H}$, Yilmaz-Keskin E, Tas $\mathrm{T}$, Gunes A, Kocamaz H, Konca C, Tas MA (2008). Neonatal tetanus in Turkey; what has changed in the last decade. BMC Infectious Diseases. 8:112.

Centers for Disease Control and Prevention (2011). Tetanus Surveillance: United States, 20012008. Weekly. 60(12): 365-369.
Cooley ML, Unger DG (1991). The role of family support in determining developmental outcomes in children of teen mothers. Child Psychiatry and Human Development. 21(3):217-234.

Davies-Adetugbo AA, Torimiro SEA, Ako-Nai KA (1998). Prognostic factors in neonatal tetanus. Trop Med \& Intl Health. 3 (1): 9-13.

Dey AC, Saha L, Shahidullah M (2011). Risk factors, morbidity and mortality of neonatal tetanus. Mymensingh Med J. 20 (1): 54-8.

Emodi IJ, Ikefuna AN, Obichukwu C (2011). Incidence and outcome of neonatal tetanus in Enugu over a 10-year period. South African Journal of Child Health. 5(4).

Ertem M, Cakmak A, Saka G, Ceylan A (2004). Neonatal tetanus in the south-eastern region of Turkey: changes in prognostic aspects by better health care. J Tropic Pediatr. 50: 297300.

Geronimus AT, Korenman S (1993). Maternal youth or family background? On the health disadvantages of infants with teenage mothers. American Journal of Epidemiology. 137 (2):213-225.

Hassan B, Popoola A, Olokoba A, Salawu FK (2011). A survey of neonatal tetanus at a district general hospital in north-east Nigeria. Trop. Doct. 41 (1):18-20.

Lambo JA, Memon MI, Khahro ZH, Lashari MI (2011). Epidemiology of neonatal tetanus in rural Pakistan. J Pak Med Assoc. 61(11): 1099103.

Ogunlesi TA, Okeniyi JAO, Owa JA, Oyedeji GA (2001). Neonatal tetanus at the close of the 20th century in Nigeria. Trop. Doct. 37(3): 165167.

Omoigberale Al, Abiodun PO (2005). Upsurge in neonatal tetanus in Benin City, Nigeria. East African Medical Journal. 82 (2).

Onalo R, Ishiaku HM, Ogala WN (2011). Prevalence and outcome of neonatal tetanus in Zaria, Northwestern Nigeria. J Infect Dev Ctries. 5(4): 255-259.

Oruamabo RS (2007). Neonatal tetanus in Nigeria: does it still pose a major threat to neonatal survival? Arch dis child. 92: 9-10.

Oyedeji OA, Fadero F, Joel-Medewase V, Elemile $P$, Oyedeji GA (2012). Trends in neonatal and post-neonatal tetanus admissions at a Nigerian teaching hospital. J. Infect. Dev. Ctries. 6(12):847-853. 
Pan American Health Organization (2005). Roper MH, Vandelaer JH, Gasse FH (2008). Neonatal tetanus elimination field guide 2nd edition.

Peterside O, Duru C, George B (2012). Neonatal Tetanus At The Niger Delta University Teaching Hospital: A 5 Year Retrospective Study. The Internet Journal of Pediatrics and Neonatology. 14(2). Maternal and neonatal tetanus. Lancet; 371 : 385-386.

World Health Organization (2006). WHO position on tetanus vaccine. Weekly epidemiological record. 81:197-208.

World Health Organization (2008) Tetanus. Available from: http://www.who.int/immunization/topics/tetanus/ en/index.html (accessed 14th January 2013).

\footnotetext{
Cite this Article: Babatunde OA, Adebara VO, Atoyebi OA, Oluwagbemi OA, 2014. Neonatal Tetanus in Federal Medical Center, Ido-Ekiti, South West Nigeria in a five year Retrospective Study. Greener Journal of Medical Sciences. 4(2)042-047, http://doi.org/10.15580/GJMS.2014.2.062014273.
} 